\title{
Perilaku Lentur Balok Beton dengan Lapisan Geotextile pada Daerah Tarik dan Tekan
}

\author{
Progustin Mangngi*1, Jonie Tanijaya ${ }^{* 2}$, Suryanti R Tonapa ${ }^{3}$ \\ *1 Mahasiswa Program Studi Teknik Sipil, Universitas Kristen Indonesia Paulus Makassar, \\ Indonesia mprogustin@gmail.com \\ *2,3 Dosen Program Studi Teknik Sipil, Universitas Kristen Indonesia Paulus Makassar, Indonesia ${ }^{2}$

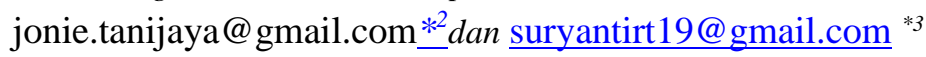

Corresponding Author: suryantirt19@gmail.com

\begin{abstract}
Abstrak
Penelitian ini bertujuan untuk mengetahui perbandingan kualitas antara beton yang menggunakan geotextile dengan beton yang tidak menggunakan geotextile. Geotextile merupakan material yang mempunyai nilai kuat tarik yang besar dan dapat digunakan untuk perkuatan tanah.. Benda uji dibuat dengan metode ACI yang berbentuk silinder $(150$ x $300 \mathrm{~mm})$ sebanyak 9 benda uji serta balok (600x150x150 mm) sebanyak 9 benda uji yang akan ditambahkan geotextile woven dan non woven. Hasil penelitian kuat tekan sebesar 20,655 MPa, 30,652 MPa, dan 32,538 MPa. Untuk nilai kuat lentur tanpa geotextile sebesar 3,526 MPa, balok beton dengan geotextile woven sebesar 4,635 $\mathrm{MPa}$, dan balok beton yang menggunakan geotextile non woven sebesar 4,282 MPa. Jadi dapat diketahui bahwa balok beton yang menggunakan geotextile woven memiliki nilai kuat lentur lebih besar dari pada balok beton tanpa geotextile dan balok beton yang menggunakan geotextile non woven.
\end{abstract}

Kata kunci: geotextile, woven, non woven, kuat tekan, kuat lentur

\begin{abstract}
This study aims to determine the quality comparison between concrete that uses geotextile and concrete that does not use geotextile. Geotextile is a material that has a large tensile strength value and can be used to strengthen the soil. The specimens were made using the ACI method in the form of cylinders (150 x $300 \mathrm{~mm})$ as many as 9 specimens and 9 beams (600x150x150 mm) to which woven and non-woven geotextiles were added. The results of this research are the compressive strength of 20,655 MPa, 30,652 MPa, and 32,538 MPa. The flexural strength value without geotextile is 3,526 $\mathrm{MPa}$, concrete beam with woven geotextile is 4,635 MPa, and concrete beam using non woven geotextile is 4,282 MPa. So it can be seen that concrete blocks using woven geotextiles have a greater flexible value than concrete blocks without geotextiles and concrete blocks using non-woven geotextiles.
\end{abstract}

Keywords: geotextile, woven, non woven, compressive strength, flexural strength

\section{PENDAHULUAN}

Beton merupakan material yang sangat banyak digunakan dalam bidang konstruksi saat ini. Kemajuan dari bahan bangunan dapat terlihat dari berbagai macam material yang ada di dalam campuran beton. Bahan campurkan tersebut dimaksudkan untuk menambah kualitas beton. Material yang dimaksud seperti geosynthetic. Geosynthetic sangat banyak digunakan pada perkuatan beton dan perkuatan tanah seperti 
geotextile [1]. Selain geotextile salah satu material yang bisa digunakan sebagai bahan perkuatan eksternal ialah Fiberglass Reinforced Plastic (FRP). Penggunaan material FRP sebagai perkuatan eksternal di lingkungan ekstrim menghasilkan pola retak lentur dan model keruntuhan yang terjadi pada balok beton yang diperkuat dengan FRP ialah kegagaln lekatan [2].

Penggunaan geotextile yang paling umum digunakan adalah pada stabilisasi tanah, perkuatan tanah timbunan, perkuatan lapis perkerasan jalan, dan perkuatan rel kereta api. Selain itu geotextile dapat digunakan untuk perkuatan pada dinding penahan tanah, abutment, gorong-gorong berbentuk kotak, dan penahan limbah. Hasil yang diperoleh dari penggunaan bahan geotextile adalah durabilitas bangunan dan umur bangunan lebih lama [3]. Manfaat lain dari geotextile adalah dapat menggantikan karung goni selama proses perawatan beton geotextile juga tahan terhadap cuaca sehingga beton lebih tahan lama. Geomembran, adalah geosynthetic yang kedap air, yang biasa digunakan sebagai penghalang zat cair [4].

Penggunaan geotextile dengan beton dapat direkatkan dengan sikadur $31 \mathrm{CF}$ normal apabila geotextile tersebut tidak diberi lubang agar daya ikat antara geotextile dan beton menjadi kuat [5]. Penggunaan geotextile dalam beton sebagai fiber pada daerah tarik dan tekan sangat berpengaruh terhadap kekuatan dari beton tersebut. Pemakaian geosynthetic dalam beton yaitu sebagai fiber. Salah satu sampel material geosynthetic yaitu geotextile [6].

Banyaknya jumlah lapisan geotextile dalam campuran beton maka akan semakin bagus kekuatan dari beton tersebut. Pengaruh jumlah lapisan geotextile sebagai perkuatan memberikan pengaruh yang baik dalam meningkatkan stabilitas benda uji [7]. Selain itu penggunaan beberapa lapis geotextile pada beton memberikan nilai kuat lentur pada balok beton yang baik. Benda uji yang diperkuat dengan geotextile memiliki kekuatan yang besar terhadap daya dukung dan nilai kuat lenturnya tinggi [8].

Penelitian ini bertujuan untuk mengetahui perbandingan kualitas antara beton yang menggunakan geotextile dengan beton yang tidak menggunakan geotextile.

1. Bahan Penyusun Beton.

a. Portland Composite Cement (PCC) merupakan material hasil kombinasi dari bubuk semen portland dengan bubuk bahan anorganik lainnya [9].

b. Agregat kasar (batu pecah) merupakan hasil dari pengikisan batuan dari pabrik pemecah batu dengan ukuran butir sekitar $4,75 \mathrm{~mm}-40 \mathrm{~mm}$.

c. Agregat halus ialah pasir alam yang lolos saringan No.4 dan tertahan di saringan No.200, yang berpengaruh dalam campuran beton pada kekuatan dan keawetan dari beton yang diharapkan.

d. Air adalah salah satu bahan yang dibutuhkan dalam proses pembuatan beton sebagai bahan campuran dengan cara mengaduk antara semen dengan agregat. Semen dan Air akan melakukan suatu proses kimiawi. Jumlah air yang akan digunakan pada suatu pengerjaan beton perlu diperhatikan apakah banyak atau sedikit dikarenakan akan mempengaruhi kekuatan dari beton.

e. Bahan tambah pada balok beton yaitu geotextile yang merupakan lembaran sintetis berpori yang bersifat permeabilitas dan fleksibilitas terhadap air, yang biasa digunakan sebagai penstabil jalan pada bidang sipil. Geotextile terdiri dari dua jenis yaitu geotextile woven dan geotextile non-woven [10].

2. Sifat Mekanik Beton

a. Kuat Tekan Beton

Kuat tekan beton yaitu beban persatuan luas, mengakibatkan beton akan rusak apabila diberikan gaya tekan yang tidak menentu dari mesin. Kuat tekan yang digunakan untuk mengetahui nilai kuat tekan rencana $\left(f^{\prime} c\right)$ sebesar $30 \mathrm{Mpa}$, rumus yang digunakan pada perhitungan kuat tekan pada beton yaitu :

$$
f_{c}^{\prime}=\frac{\mathrm{P}}{\mathrm{A}}
$$




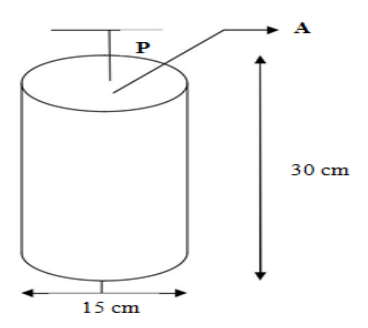

Gambar 1. Uji Kuat Tekan

b. Kuat lentur Beton

Pengujian ini dilakukan untuk mengetahui kemampuan dari balok beton untuk menahan gaya tegak lurus terhadap sumbu benda uji hingga patah yang diletakkan pada dua penyangga, perhitungan yang digunakan pada pengujian ini yaitu :

$$
\begin{aligned}
& f r=\frac{P x L}{b x h^{2}} \\
& f r=\frac{P x a}{b x h^{2}}
\end{aligned}
$$

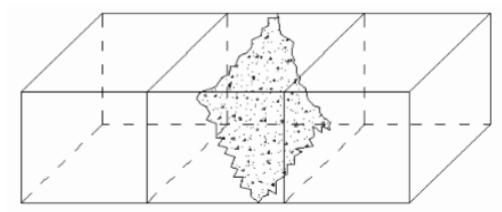

Gambar 2. Patah dari $\frac{1}{3}$ bentangan tengah

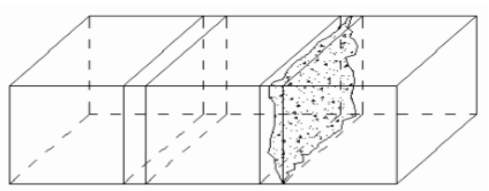

\section{Gambar 3. Patah dari $\frac{1}{3}$ bentangan tengah dan garis patahan dari $<5 \%$ pada bentangan}

Pada penelitian kuat lentur balok beton bertulang dengan kakian bambu wulung tipe $\mathrm{V}$ dengan interval $2 \mathrm{~cm}$ dan $3 \mathrm{~cm}$ terjadi retak seperti yang diinginkan, dengan rata-rata kegagalan terjadi pada $1 / 3$ bagian tengah balok dan di titik pusat beban pada 12 benda uji [11]. Keruntuhan yang terjadi pada beton dengan geotextile dapat terjadi pada penempatan agregat dan pada saat proses pemadatan yang mengakibatkan tegangan yang tinggi pada geotextile. Umumnya kerusakan geotextile terjadi pada saat pemasangan dan konstruksi [12]. Selain itu panjang geotextile yang digunakan juga berpengaruh sebagai bahan perkuatan. Panjang geotextile yang memenuhi syarat yaitu $\mathrm{L} / \mathrm{H}=0,22$ sampai $\mathrm{L} / \mathrm{H}=0,83$ [13].

\section{METODOLOGI}

Lembaran geotextile diperoleh dari pabrik PT. Indotex Bangun Mandiri, di Jln. Benteng Betawi No.35, kota Tangerang, Banten

\section{Pemeriksaan Karakteristik Material}

Material yang dipakai pada penelitian ini terlebih dahulu diperiksa untuk mengetahui kualitas dari agregat tersebut. 
Tabel 1. Spesifikasi agregat halus

\begin{tabular}{ccc}
\hline Karakteristik Agregat Halus & Interval Batas & Pedoman \\
\hline Kadar lumpur, $\%$ & $0,2-6$ & SNI 03-4142:1996 \\
\hline Kadar organik, warna & $<$ No.3 & $2816: 2014$ \\
\hline Kadar air, $\%$ & $3-5$ & SNI 03-1971:2011 \\
\hline Berat volume padat, $\mathrm{kg} / \mathrm{ltr}$ & $1,40-1,90$ & SNI 03-4804:1998 \\
\hline Berat volume gembur, $\mathrm{kg} / \mathrm{ltr}$ & $0,20-2,00$ & SNI 03-4804:1998 \\
\hline Penyerapan, $\%$ & $0,20-2,00$ & SNI 1970:2008 \\
\hline Berat jenis (SSD) & $1,6-3,2$ & SNI 1970:2008 \\
\hline Modulus kehalusan & $2,20-3,10$ & SNI 03-1968:1990
\end{tabular}

Tabel 2. Spesifikasi agregat kasar

\begin{tabular}{ccc}
\hline Karakteristik Agregat Kasar & Interval Batas & Pedoman \\
\hline Kadar Lumpur, $\%$ & $0,2-1,0$ & SNI 03-4142-1996 \\
\hline Kadar Air, $\%$ & $0,5-2,0$ & SNI 03-1971-2011 \\
\hline Lanjutan tabel spesifikasi agregat halus & & \\
\hline Berat volume padat, kg/ltr & $1,40-1,90$ & SNI 03-4804-1998 \\
\hline Berat volume gembur, kg/ltr & $1,40-1,90$ & SNI 03-4804-1998 \\
\hline Penyerapan, $\%$ & $0,20-2,00$ & SNI 1969-2008 \\
\hline Berat jenis SSD & $1,60-3,20$ & SNI 1969-2008
\end{tabular}

Tabel 3. Spesifikasi Geotextile Woven (Anyam)

\begin{tabular}{cc}
\hline Sifat - sifat & Nilai \\
\hline Tipe Gramasi & $250 \mathrm{gr}$ \\
\hline Tebal & $\pm 1,96 \mathrm{~mm}$ \\
\hline Kekuatan Tarik & $51-55 \mathrm{kN}$ \\
\hline
\end{tabular}

Tabel 4. Spesifikasi Geotextile Non - Woven (Polos)

\begin{tabular}{cc}
\hline Sifat - sifat & Nilai \\
\hline Tipe Gramasi & $250 \mathrm{gr}$ \\
\hline Tebal & $\pm 1,96 \mathrm{~mm}$ \\
\hline Kekuatan Tarik & $8,87-11,76 \mathrm{kN}$ \\
\hline
\end{tabular}

\section{Perencanaan campuran beton}

Perencanaan dalam proses pembuatan beton yang dilakukan pada penelitian ini sesuai dengan metode $A C I$ (American Concrete Institute).

\section{Identifikasi benda uji}

Sampel yang digunakan berbentuk silinder 15 x $30 \mathrm{~cm}$ untuk pengujian kuat tekan dan balok dengan dimensi 60x15x15 cm pada pengujian kuat lentur. 
Tabel 5. Identifikasi Sampel

\begin{tabular}{|c|c|c|c|c|}
\hline No. & Pengujian & $\begin{array}{l}\text { Kode \& Umur } \\
\text { Pengujian }\end{array}$ & $\begin{array}{c}\text { Variasi } \\
\text { Geotextile }\end{array}$ & $\begin{array}{l}\text { Jumlah } \\
\text { Sampel } \\
\end{array}$ \\
\hline \multirow{3}{*}{1} & \multirow{3}{*}{ Kuat Tekan } & KT1 (H7) & \multirow{3}{*}{$0 \%$} & 3 Sampel \\
\hline & & KT2 (H21) & & 3 Sampel \\
\hline & & KT3 (H28) & & 3 Sampel \\
\hline \multirow{3}{*}{2} & \multirow{3}{*}{ Kuat Lentur } & KLW (H28) & Woven & 3 Sampel \\
\hline & & KLNW (H28) & Non-Woven & 3 Sampel \\
\hline & & KLN (H28) & Normal & 3 Sampel \\
\hline
\end{tabular}

\section{ANALISA DAN PEMBAHASAN}

\section{Pengujian Karakteristik Agregat Halus (Pasir)}

Pengujian sifat agregat halus sesuai dengan spesifikasi SNI. Dapat terlihat pada tabel 6, sehingga pada gambar 5 diperoleh grafik pembagian butir agregat halus.

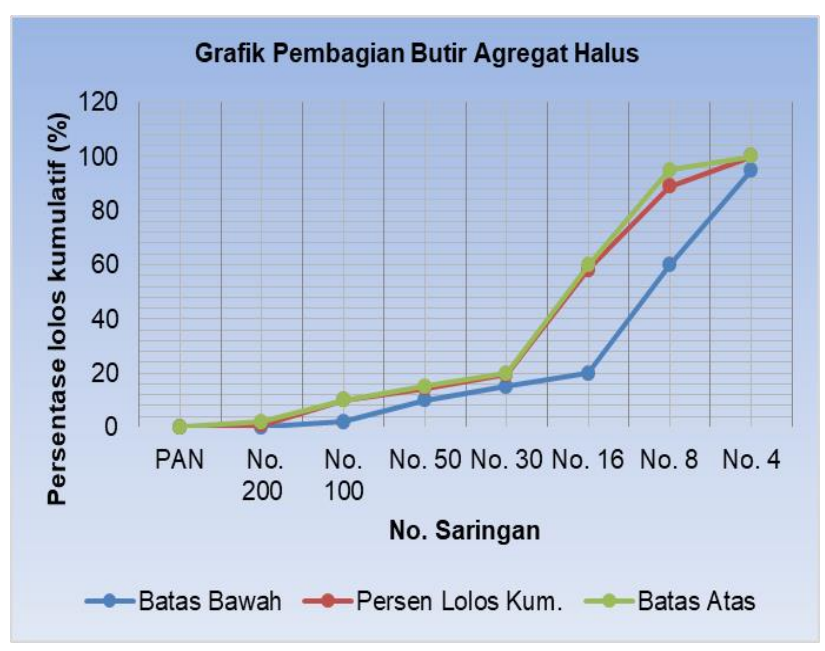

Gambar 5. Grafik pembagian butir agregat halus

Tabel 6. Pengujian Karakteristik Agregat Halus

\begin{tabular}{cccc}
\hline Karakteristik & Hasil & Interval ASTM & Keterangan \\
\hline Kadar Air & $3,989 \%$ & $3,00 \%-5,00 \%$ & Memenuhi \\
\hline Zat Organik & No.1 & $<$ No.3 & Memenuhi \\
\hline Kadar Lumpur & $5 \%$ & $0,20 \%-6,00 \%$ & Memenuhi \\
\hline Berat Jenis SSD & 2,518 & $1,60-3,20$ & Memenuhi \\
\hline Absorpsi (Penyerapan) & $1,1 \%$ & $0,20 \%-2,00 \%$ & Memenuhi \\
\hline Berat Volume Padat & $1671,667 \mathrm{~kg} / \mathrm{m}^{3}$ & $>1,200 \mathrm{~kg} / \mathrm{ltr}$ & Memenuhi \\
\hline Berat Volume Gembur & $1565 \mathrm{~kg} / \mathrm{m}^{3}$ & $>1,200 \mathrm{~kg} / \mathrm{ltr}$ & Memenuhi \\
\hline Modulus Kehalusan & 3,090 & $2,20-3,10$ & Memenuhi \\
\hline
\end{tabular}




\section{Pengujian karakteristik agregat kasar (batu pecah).}

Pengujian sifat agregat kasar sesuai dengan spesifikasi dari SNI. Pada gambar 6 diperoleh grafik pembagian butir dari agregat kasar dan pada tabel 7 merupakan spesifikasi SNI hasil pengujian agregat kasar.

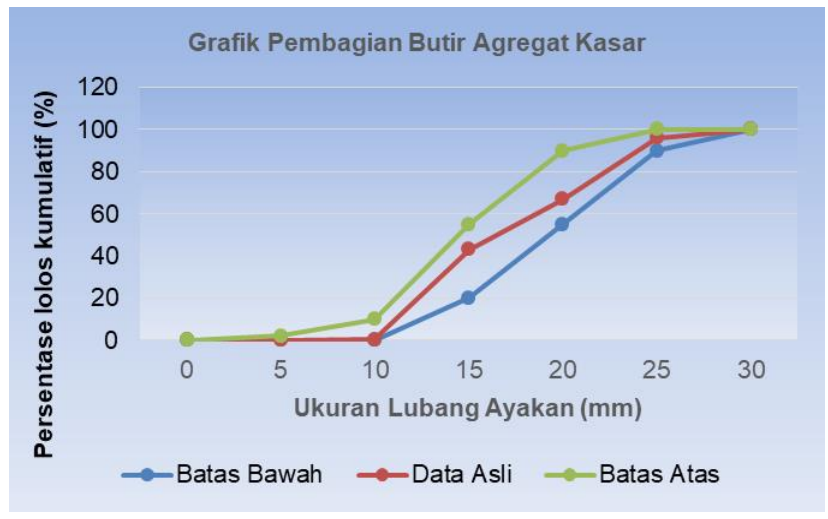

Gambar 6. Grafik pembagian butir agregat kasar

Tabel 7. Pemeriksaan Karakteristik Agregat Kasar

\begin{tabular}{cccc}
\hline Karakteristik & Hasil & Interval ASTM & Keterangan \\
\hline Kadar Air & $0,705 \%$ & $0,50 \%-2,00 \%$ & Memenuhi \\
\hline Kadar Lumpur & $0,26 \%$ & $0,2 \%-1,00 \%$ & Memenuhi \\
\hline Berat Volume Padat & $1576 \mathrm{~kg} / \mathrm{liter}$ & $1400-1900 \mathrm{~kg} / \mathrm{ltr}$ & Memenuhi \\
\hline Berat Volume Gembur & $1485,714 \mathrm{~kg} / \mathrm{liter}$ & $1400-1900 \mathrm{~kg} / \mathrm{ltr}$ & Memenuhi \\
\hline Berat Jenis SSD & 2,613 & $1,60-3,20$ & Memenuhi \\
\hline Absorpsi (Penyerapan) & $1,317 \%$ & $0,20 \%-2,00 \%$ & Memenuhi \\
\hline
\end{tabular}

\section{Mix Design Menggunakan Metode ACI}

Mix design merupakan proses desain dan pemilihan bahan yang sesuai dan terjangkau dengan maksud beton yang dibuat sesuai dengan yang diharapkan

Sesuai dengan hasil pemeriksaan dan perhitungan pada mix design, komposisi/proporsi agregat yang akan digunakan pada penelitian ini dapat dilihat pada tabel 8 .

Tabel 8. Komposisi Kebutuhan yang akan digunakan dalam Campuran Beton

\begin{tabular}{ccccc}
\hline Material & Semen (kg) & $\begin{array}{c}\text { Agregat Halus } \\
(\mathbf{k g})\end{array}$ & $\begin{array}{c}\text { Agregat Kasar } \\
(\mathbf{k g})\end{array}$ & $\begin{array}{c}\text { Air } \\
(\mathbf{l i t e r})\end{array}$ \\
\hline 1 Silinder & 2,362 & 3,442 & 5,428 & 1,022 \\
\hline 1 Balok & 6,017 & 8,770 & 13,839 & 2,606 \\
\hline Perbandingan & 1 & 1,457 & 2,299 & 0,433 \\
\hline
\end{tabular}

\section{Pengujian Kuat Tekan Beton}

Pengujian kuat tekan beton dilakukan pada saat beton berumur 7, 21, dan 28 hari dengan kuat tekan rencana $\left(f^{\prime} c\right)$ sebesar 30 Mpa. Hasil pengujian kuat tekan beton dapat dilihat pada tabel 9 dan diperoleh grafik kuat tekan beton pada umur 7,21,dan 28 hari yang dapat dilihat pada gambar 7 . 


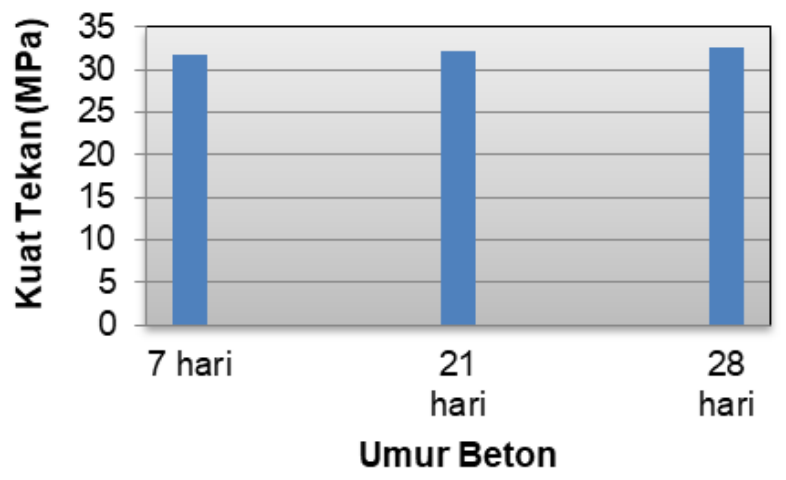

Gambar 7. Grafik Kuat tekan beton berdasarkan umur.

Tabel 9. Hasil pengujian Beton Kuat Tekan (Normal)

\begin{tabular}{|c|c|c|c|c|c|c|}
\hline $\begin{array}{c}\text { Agregat } \\
\text { Kasar }\end{array}$ & $\begin{array}{l}\text { Umur } \\
\text { (Hari) }\end{array}$ & $\begin{array}{c}\text { Beban } \\
\text { Maksimum } \\
(\mathbf{k N})\end{array}$ & $\begin{array}{l}\text { Kuat } \\
\text { Tekan } \\
\text { Beton } \\
\text { Aktual } \\
(\mathrm{MPa})\end{array}$ & $\begin{array}{c}\text { Kuat Tekan } \\
\text { Beton } \\
\text { Aktual } \\
\text { Rata-rata } \\
\text { (Mpa) }\end{array}$ & $\begin{array}{c}\text { Kuat } \\
\text { Tekan } \\
\text { Konversi } \\
28 \text { hari } \\
\text { (MPa) }\end{array}$ & $\begin{array}{l}\text { Kuat Tekan } \\
\text { Konversi } 28 \\
\text { hari (MPa) }\end{array}$ \\
\hline \multirow{9}{*}{$\begin{array}{l}\text { Kerikil } \\
(100 \%)\end{array}$} & \multirow{3}{*}{7} & 370 & 20,938 & \multirow{3}{*}{20,655} & 32,212 & \multirow{3}{*}{31,777} \\
\hline & & 360 & 20,372 & & 31,341 & \\
\hline & & 365 & 20,655 & & 31,777 & \\
\hline & \multirow{3}{*}{21} & 550 & 31,124 & \multirow{3}{*}{30,652} & 32,762 & \multirow{3}{*}{32,265} \\
\hline & & 540 & 30,558 & & 32,166 & \\
\hline & & 535 & 30,275 & & 31,868 & \\
\hline & \multirow{3}{*}{28} & 590 & 33,387 & \multirow{3}{*}{32,538} & 33,387 & \multirow{3}{*}{32,538} \\
\hline & & 570 & 32,255 & & 32,255 & \\
\hline & & 565 & 31,972 & & 31,972 & \\
\hline
\end{tabular}

\section{Pengujian Kuat Lentur Beton}

Tahapan pengujian yang digunakan sesuai dengan SNI 4431-2011, sampel yang digunakan adalah balok dengan dimensi $150 \times 150 \times 600 \mathrm{~mm}$, alat uji kuat lentur dilengkapi dengan dua titik pembebanan. Pengujian dilakukan pada saat umur beton 28 hari Hasil uji kuat lentur dapat dilihat pada tabel 10.

Tabel 10. Hasil Pengujian Kuat Lentur beton dengan Balok Normal

\begin{tabular}{cccc}
\hline Variasi & $\begin{array}{c}\text { Beban Maksimum } \\
\text { (Ton) }\end{array}$ & $\begin{array}{c}\text { Kuat Lentur Beton } \\
\text { (MPa) }\end{array}$ & $\begin{array}{c}\text { Kuat Lentur Beton Rata- } \\
\text { rata (MPa) }\end{array}$ \\
\hline \multirow{3}{*}{ Tanpa Geotextile } & 2.5 & 3.777 & \\
& 2.3 & 3.476 & 3,526 \\
\cline { 2 - 3 } & 2.2 & 3.325 & \\
\cline { 2 - 3 } Geotextile Woven & 3.4 & 5.139 & \multirow{2}{*}{4,635} \\
\cline { 2 - 3 } & 3.0 & 4.534 & \\
\hline \multirow{2}{*}{$\begin{array}{c}\text { Geotextile Non } \\
\text { Woven }\end{array}$} & 2.8 & 4.232 & \multirow{2}{*}{4,282} \\
\cline { 2 - 3 } & 3.1 & 4.686 & \\
\hline
\end{tabular}



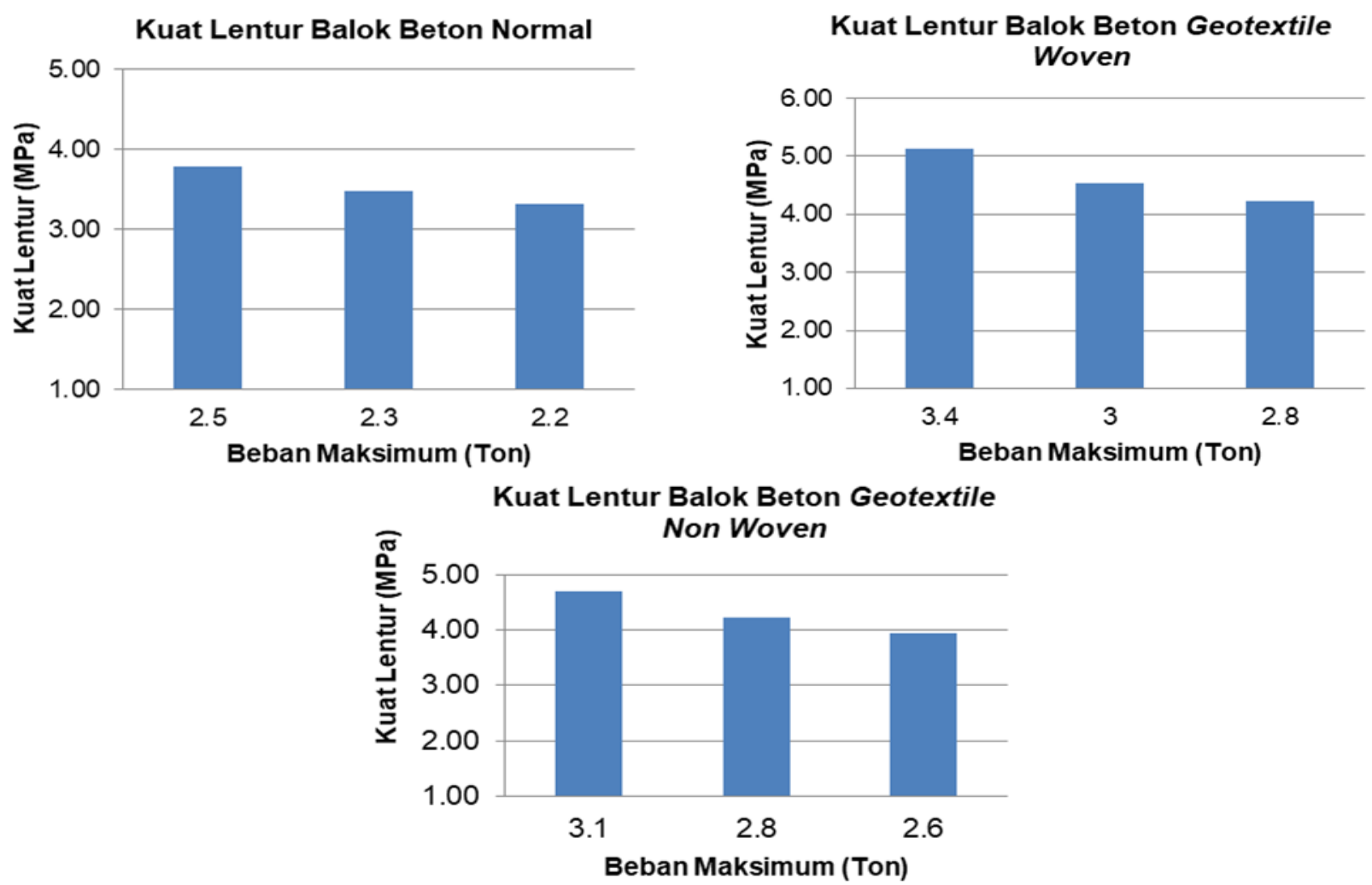

\section{Gambar 8. Grafik Kuat Lentur}

6. Hubungan Antara Kuat Tekan dengan Kuat Lentur Beton.

Dari hasil penelitian yang dilakukan diperoleh nilai kuat tekan beton secara berturut-turut 33,387 MPa, 32,255 $\mathrm{MPa}, 31,972 \mathrm{MPa}$. Untuk nilai kuat lentur beton tanpa geotextile $3.777 \mathrm{MPa}$, 3,476 $\mathrm{MPa}$, dan 3,325MPa.

Tabel 11. Parameter Kuat Tekan dengan Kuat Lentur balok normal

\begin{tabular}{ccccc}
\hline \multirow{2}{*}{ Benda Uji } & Kuat Lentur $(\boldsymbol{f} \boldsymbol{r})$ & Kuat Tekan $\left(\boldsymbol{f}^{\prime} \boldsymbol{c}\right)$ & \multicolumn{2}{c}{ Perbandingan } \\
\cline { 2 - 5 } & $\mathbf{( M p a )}$ & $\mathbf{M p a})$ & $\sqrt{\boldsymbol{f}^{\prime} \boldsymbol{c}}$ & $\frac{\boldsymbol{f}_{\boldsymbol{r}}}{\sqrt{\boldsymbol{f}^{\prime} \boldsymbol{c}}}$ \\
\hline $\mathbf{1}$ & 3,777 & 33,387 & 5,778 & 0,654 \\
\hline $\mathbf{2}$ & 3,476 & 32,255 & 5,679 & 0,612 \\
\hline $\mathbf{3}$ & 3,325 & 31,972 & 5,654 & 0,588 \\
\hline
\end{tabular}

Berdasarkan tabel diatas nilai kuat lentur yang didapat yaitu $0.654 \sqrt{f^{\prime} c}, 0.612 \sqrt{f^{\prime} c}, 0.588 \sqrt{f^{\prime} c}$ dilihat dari nilai kuat tekan betonnya, dengan demikian dapat diperoleh nilai rata-rata hubungan antara kuat tekan dengan kuat lentur sebesar 0,62 sehingga persamaan yang dituliskan yaitu :

$$
f r=0,62 \sqrt{f^{\prime} c}
$$

\section{KESIMPULAN}

Dari hasil pengujian dapat diketahui bahwa nilai kuat lentur balok beton tanpa geotextile yang diperoleh sebesar 3,526 Mpa, nilai kuat lentur balok beton dengan penggunaan geotextile jenis woven sebesar 4,635 Mpa, dan nilai kuat lentur balok beton dengan penggunaan geotextile jenis non woven sebesar 4,282 Mpa. Perbandingan antara nilai kuat lentur balok beton tanpa geotextile dengan balok beton dengan geotextile 
woven sebesar $31,452 \%$, balok beton tanpa geotextile dengan balok beton yang menggunakan geotextile non woven sebesar $21,441 \%$, dan untuk nilai kuat lentur balok beton yang menggunakan geotextile woven dengan balok beton yang menggunakan geotextile non woven sebesar $8,244 \%$.

Dari hasil pengujian, balok beton yang menggunakan geotextile memiliki nilai kuat lentur lebih besar dari pada balok beton yang tidak menggunakan geotextile.

\section{DAFTAR PUSTAKA}

[1] L.F. Jodie Saputra, "Uji Lentur dan Tarik Pada Beton Dengan Geotextile," J. Dimensi Pratama Teknik Sipil, vol.7, no.2, hlm. 129-135, 2018.

[2] A.S.Setiawan,A.M.N.Padli,M.Y.Ali,E.Bachtiar,V.Tandioga, dan C.N.Fitriany, "Perilaku Lentur Balok Beton Pada Kombinasi Daerah Geser dan Tarik yang Menggunakan Material FRP Sebagai Perkuatan Eksternal di Lingkungan Ekstrim," Indonesia Journal of Fundamental Sciences, vol. 6, no. 2, hlm. 147-156, 2020.

[3] F.X.Ndale, "Penggunaan Geotextile Sebagai Bahan Bangunan," TEKNOSIAR, vol. 13, no. 2, hlm. 64-73, 2020.

[4] R.D.Holtz, "Geosynthetic For Soil Reinforcement," Department of Civil \& Environmental Engineering University of Washington, hlm. 181-194, 2001.

[5] J.H. Long, "Bound Strength Between Geotextile and Concrete," International Journal of Applied Engineering Research, vol 8, no.2, hlm.113-132, 1989.

[6] K.Rajeshkumar., N. Mahendran dan R. Gobinath, "Experimental Studies on Viability of Using Geosynthetics as Fibers in Concrete". International Journal of Applied Engineering Research, vol. 1, no. 1, ISSN: 0976-4259, hlm. 15-28, 2010.

[7] A.Tolooiyan, M.R.Slelamat, Sh.Ghaffari I.Abustan, "A Comprehensive Method for Analyzing Effect of Geotextile Layer on Embankment Stability," International Journal of Applied Engineering Research, vol. 27, no. 5, hlm.399-405, 2009.

[8] Anita Widianti, "Pengaruh Jumlah Lapisan dan Spasi Perkuatan Geosintetik," Jurnal Ilmiah Teknika Semesta, vol. 15, no. No. 1, hlm. 90-97, 2012.

[9] SNI 15-7064 : 2004, "Semen Portland Komposit".

[10] S. Tria Dika Kumala, "Penggunaan Geotextile Non Woven Pada Proyek Peningkatan Jalan Anjir PasarMarabahan," Bulotin Profesi Insinyur 1 (2), hlm. 78-82, 2018.

[11] A.S.Budi, dan Sunarmatso U.Kultsum, "Kajian Kuat Lentur Balok Beton Bertulangan Bambu Wulung Takikan Tipe V dengan Jarak $2 \mathrm{~cm}$ dan $3 \mathrm{~cm}$," MATRIKS TEKNIK SIPIL, vol. 5, no. 2, hlm. 61-72, 2019.

[12] R.M Koerner, "Designing With Geosynthetics Second Edition," Prentice Hall Inc, 1990.

[13] Yun Hu, Ga Zhang, Jian-Min Zhang, C.F.Lee "Centrifuge Modeling of Geotextile Reinforced Cohesive Slopes," Canadian Geotechnical Journal, vol. 28, no.1,hlm.12-22, 2010.

[14] Tjokrodimulyono, "Teknologi Beton," Jurusan Teknik Sipil Fakultas Teknik Universitas Gadjah Mada, Yogyakarta, 2007.

[15] Jonie. Tanijaya, "Panduan Praktikum Beton," Laboratorium Struktural dan Bahan Program Studi Teknik Sipil Fakultas Teknik Universitas Kristen Indonesia Paulus Makassar, 2007. 